\title{
ANALISIS VARIABEL PENGURANGAN BIAYA OVERHEAD LAPANGAN YANG DOMINAN PADA PROYEK KONSTRUKSI GEDUNG BERTINGKAT DI JAKARTA
}

\author{
Calvin Christian' ${ }^{1}$ dan Basuki Anondho² \\ ${ }^{1}$ Program Studi Sarjana Teknik Sipil, Universitas Tarumanagara, Jl. Letjen S. Parman No.1 Jakarta \\ Email: christian.calvin42@yahoo.com \\ ${ }^{2}$ Program Studi Sarjana Teknik Sipil, Universitas Tarumanagara, Jl. Letjen S. Parman No.1 Jakarta \\ Email: basukia@ft.untar.ac.id
}

\begin{abstract}
ABSTRAK
Proyek konstruksi merupakan kegiatan yang dibatasi oleh waktu dan sumber daya seperti biaya, material, peralatan, dan manusia sehingga membutuhkan manajemen proyek mulai dari fase koseptual hingga fase implementasi Dalam proses konstruksi bangunan, pada umumnya biaya konstruksi dibagi menjadi dua bagian yaitu biaya langsung dan biaya tidak langsung, biaya tidak langsung ini salah satunya adalah biaya overhead. Tujuan dari penelitian ini adalah untuk mengetahui jenis pengelolaan biaya overhead lapangan yang digunakan pada proyek gedung bertingkat tinggi di Jakarta melalui metode analaisis faktor. Analisis Faktor ini dilakukan untuk menguji jenis -jenis pengelolaan biaya overhead yang digunakan pada proyek gedung bertingkat tinggi yang ada di jakarta. Penyebaran kuisioner dan pengambilan data proyek ongoing dilakukan pada wilayah Jakarta dan sekitarnya. Analisis. Hasil analisis menunjukkan bahwa terdapat enam jenis pengelolaan yang umum digunakan pada proyek gedung bertingkat di Jakarta,yaitu pengawasan proyek, akurasi penyelesaian proyek, kegiatan berbasis $\mathrm{ABC}$ (Activity Based Costing), inovasi, pemberian gaji tepat waktu, dan efektivitas pekerja.
\end{abstract}

Kata kunci: biaya proyek, biaya tidak langsung, biaya overhead, analisis faktor .

\section{PENDAHULUAN}

\section{Latar belakang}

Proyek Konstruksi merupakan kegiatan yang dibatasi oleh waktu dan sumber daya seperti biaya, material, peralatan, dan manusia sehingga membutuhkan manajemen proyek mulai dari fase koseptual hingga fase implementasi. Semakin tinggi tingkat kompleksitas proyek dan semakin langkanya sumber daya maka akan dibutuhkan juga sitem pengelolaan dan pengendalian proyek yang lebih baik dan terintegrasi (Watimurry, et.al.,2015).

El Sawy (2011) menyatakan bahwa memperkirakan biaya overhead untuk proyek konstruksi merupakan hal penting dalam manajemen proyek. Walaupun biaya overhead merupakan salah satu hal terpenting dalam estimasi biaya konstruksi, hal tersebut sering kali diabaikan oleh kontraktor. Mengabaikan biaya overhead telah banyak menyebabkan kontraktor mengalami kegagalan usaha, karena biaya-biaya ini merupakan bagian yang signifikan dari total biaya konstruksi (Assaf et al. 2001).

Berdasarkan tinjauan literatur yang ada, dapat dikatakan bahwa biaya overhead menjadi fokus utama bagi banyak peneliti, terutama dalam hal proyek konstruksi. Chan (2012) melakukan eksplorasi faktor-faktor utama yang mempengaruhi biaya overhead proyek konstruksi . Ketika suatu proyek tertunda , biaya overhead dapat bertambah besar, yang berarti bahwa proyek tersebut membutuhkan waktu yang lebih lama dari waktu yang dijanjikan di kontrak. Biaya ini terus bertambah dan akan berasal dari keuntungan kontraktor.

Atas dasar hal - hal tersebut diatas, maka dirasa perlu untuk melakukan suatu studi tentang jenis pengurangan biaya overhead lapangan yang dipergunakan pada proyek - proyek konstruksi di Jakarta.

\section{TINJAUAN PUSTAKA}

\section{Biaya proyek konstruksi}

Menurut Soeharto (1995), Biaya merupakan salah satu faktor terpenting dalam manajemen proyek konstruksi. Oleh karena itu, biaya perlu dikendalikan agar sesuai dengan budget yang telah disepakati sehingga tidak terjadi kerugian yang tidak diinginkan. Salah satu cara untuk mengendalikan biaya adalah dengan cara cost estimating (perkiraan biaya). Cost estimating (perkiraan biaya) merupakan pekerjaan yang membuat sebuah estimasi dari sumber daya 
dan biaya yang diperlukan dalam menyelesaikan suatu proyek konstruksi. Lebih lanjut, Soeharto (1995) menyatakan bahwa perkiraan biaya memegang peranan penting dalam penyelenggaraan proyek.

Biaya konstruksi adalah biaya yang dikeluarkan untuk menjalankan suatu proyek. Kebijakan pembiayaan biasanya dipengaruhi oleh kondisi keuangan perusahaan yang bersangkutan. Menurut Ariyanto ( 2003), bila kondisi keuangan tidak dapat menunjang kegiatan pelaksanaan proyek, dapat ditempuh dengan beberapa cara, yaitu:

1. Peminjaman kepada bank atau lembaga keuangan untuk keperluan pembiayaan secara tunai agar dapat menekan biaya, namun harus membayar bunga pinjaman

2. Tidak meminjam uang, namun menggunakan kebijakan kredit barang atau jasa yang diperlukan. Dengan menggunakan cara ini akan dapat menghindari bunga pinjaman, namun harga yang diperoleh lebih tinggi dibandingkan dengan cara tunai.

Dalam melakukan estimasi biaya proyek secara keseluruhan tentunya memiliki komponen-komponen yang menentukan besaran total biaya proyek tersebut. Menurut AACE (1992), struktur dari biaya konstruksi terdiri dari dua komponen utama, yaitu biaya langsung (direct cost) dan biaya tidak langsung (indirect cost).

\section{Biaya tidak langsung}

Biaya tak langsung adalah biaya yang tidak secara langsung berhubungan dengan konstruksi / bangunan tetapi harus ada dan tidak dapat dilepaskan dari proyek tersebut, diantaranya adalah (Faiz, 2007) :

\section{Biaya Overhead}

Biaya overhead dapat digolongkan menjadi 2 jenis biaya yaitu :

- Overhead Proyek (dilapangan), diantaranya adalah :

- Biaya personil di lapangan;

- Fasilitas sementara proyek seperti biaya untuk pembuatan ; gudang, kantor, penerangan, pagar, komunikasi, transportasi;

- Bank Garansi, bunga bank, ijin banunan, pajak;

- Peralatan kecil yang umumnya habis / terbuang setelah proyek selesai;

- Foto-foto dan gambar jadi (asbuild drawing);

- Kwlitas kontrol, seperti test tekan kubus / silinder beton, baja sondir , boring;

- Rapat-rapat di lapangan;

- Biaya-biaya pengukuran.

- Overhead Kantor

Adalah biaya untuk menjalankan suatu usaha, termasuk didalamnya seperti sewa kantor dan fasilitasnya, honor pegawai, ijin-ijin usaha, prakwalifikasi, referensi bank, anggota assosiasi.

2. Biaya tak terduga / Contigencies

Biaya tak terduga adalah salah satu biaya tak langsung, yaitu biaya untuk kejadian-kejadian yang mungkin terjadi atau mungkin tidak. Misalnya naiknya muka air tanah, banjir, longsornya tanah dan sebagainya. Berapa biaya yang perlu kita sediakan untuk ini . Ternyata lebih sulit dihitung dari pada biaya langsung. Pada umumnya biaya ini diperkirakan antara 0,5 sampai $5 \%$ dari biaya total proyek. Yang termasuk dalam kondisi contigencies adalah sebagai berikut :

- Akibat Kesalahan

- Ketidak Pastian Subyektif

- Ketidak Pastian Obyektif

- Variasi Efisiensi

3. Keuntungan / profit

Untuk inilah seseorang mau mengambil resiko menjadi kontraktor. Kalau tanpa keuntungan, siapa yang akan mau . Karena itulah perlu diingat bahwa keuntungan tidak sama dengan gaji. Keuntungan adalah hasil jerih payah dari keahlian, ditambah hasil dari faktor resiko. Semua jenis biaya diatas adalah biaya yang mau tidak mau harus dikeluarkan. Jadi seyogyanya tidak dapat dikurangi (kecuali mengadakan pelanggaran). Maka satu-satnya biaya yang dapat kita tambah atau dikurangi adalah keuntungan. Bila kita ingin memenangkan suatu tender sedangkan saingannya cukup banyak, maka kita berani untuk menurunkan harga penawaran dengan mengurangi keuntungan.

\section{Biaya overhead}

Cilensek (1991), mendefinisikan biaya overhead sebagai biaya-biaya yang bukan merupakan bagian dari biaya aktual konstruksi, tetapi dikenakan kepada kontraktor untuk mendukung proyek tersebut. Biaya overhead dikelompokkan menjadi dua jenis, yaitu biaya overhead kantor dan biaya overhead proyek. Biaya overhead kantor merupakan alokasi beban kantor pusat kepada proyek. Dimana biaya overhead kantor pusat adalah biaya-biaya yang 
tak langsung terlibat pada proyek konstruksi yang terdapat pada kantor pusat, yang dibebankan ke tiap proyek dengan suatu tingkat pembebanan tertentu (Taylor, 1994). Sedangkan biaya overhead proyek merupakan biaya-biaya yang terjadi di lokasi konstruksi, tetapi tidak secara langsung terkait dengan item pekerjaan (Bennett, 2003).

\section{Biaya overhead kantor}

Menurut (Zack 2001), Biaya overhead kantor adalah biaya yang menjalankan kantor permanen kontraktor dan mendukung sekelompok proyek. Mereka termasuk gaji eksekutif dan administrasi, pengeluaran hukum dan akuntansi, biaya sewa kantor, iklan, asuransi perusahaan, biaya perekrutan, utilitas, biaya hubungan manusia, bunga pinjaman perusahaan, perjalanan untuk staf kantor, utang macet, depresiasi aset perusahaan, hiburan, biaya profesional , kontribusi, dan biaya penawaran.

\section{Biaya overhead lapangan}

Menurut Dagostino, F. R. (2003), biaya overhead lapangan termasuk item yang dapat diidentifikasi dengan pekerjaan tertentu, tetapi bukan bahan, tenaga kerja, atau peralatan produksi. Overhead pekerjaan mencakup biaya-biaya itu tidak dapat ditagih langsung ke cabang pekerjaan tertentu, tetapi diminta untuk membangun proyek. Menurut Neil, J. M. (1981), pekerjaan overhead (overhead lapangan) mirip dengan overhead kantor tetapi harus didistribusikan ke proyek terkait, karena tidak bisa dialokasikan ke paket pekerjaan tertentu (Abdul-Malak. et al 2002). Peningkatan biaya overhead lapangan biasanya lebih mudah diukur. Ini mengharuskan kontraktor untuk mengungkapkan penumpukannya pengecekan lapangan, menunjukkan biaya rinci untuk semua item dianggap sebagai item umum lapangan (infrastruktur lapangan, crane, dan peralatan umum lapangan lainnya) (Abdul-Malak. et al 2002).

Berikut merupakan contoh-contoh biaya overhead lapangan :

1. Fasilitas sementara proyek seperti biaya untuk pembuatan ; gudang, kantor, penerangan, pagar, komunikasi, transportasi.

2. Bank Garansi, bunga bank, ijin banunan, pajak.

3. Peralatan kecil yang umumnya habis / terbuang setelah proyek selesai.

4. Foto-foto dan gambar jadi (asbuild drawing)

5. Kualitas kontrol, seperti test tekan kubus / silinder beton, baja sondir , boring.

6. Rapat-rapat di lapangan

7. Biaya-biaya pengukuran

8. Biaya personil di lapangan

\section{Pengendalian biaya overhead}

Menurut Swati S Patil (2014), Mengontrol biaya overhead harus selalu menjadi perhatian manajemen yang penting. Kontraktor dapat mengendalikan biaya overhead melalui beberapa langkah akal sehat tradisional yang secara signifikan mengurangi biaya overhead karena langkah-langkah ini mudah untuk dipraktekkan pada tingkat hari-demi-hari tanpa pengaturan khusus.

1. Kontraktor perlu diberi informasi lebih baik tentang biaya overhead melalui kursus singkat, seminar, masyarakat profesional dan ilmiah. Kontraktor harus sadar akan manfaat dari pengurangan biaya overhead perusahaan ke organisasi mereka dan industri konstruksi.

2. Kontraktor dapat mempertahankan tingkat optimal biaya overhead perusahaan, sehingga mencapai dua tujuan pada saat yang sama: untuk menghilangkan biaya yang tidak perlukan dan untuk dapat mengamankan atau meningkatkan harga pasar perusahaan sesuai dengan tujuan strategisnya.

3. Kontraktor direkomendasikan untuk membuat rencana pengendalian biaya untuk membantu mengurangi biaya overhead perusahaan. Rencana tersebut harus mengandung tujuan biaya, langkah implementasi, pemantauan, dan tindakan korektif.

4. Mempertahankan program keamanan yang baik membantu mengurangi biaya asuransi.

5. Kepuasaan pelanggan membantu dalam menjaga reputasi baik, dimana membantu dalam memperoleh pinjaman dan layanan keuangan lainnya dengan biaya lebih rendah.

6. Meningkatkan kesadaran biaya di antara karyawan mereka, menetapkan target biaya kelompok dengan rencana insentif dan kemudian berbagi kesuksesan dengan karyawan untuk memotivasi minat mereka dalam strategi penghematan biaya.

7. Kontraktor harus menerapkan langkah-langkah pengendalian biaya pada biaya pengawasan, biaya peralatan, konstruksi sementara, dan biaya pendanaan karena barang-barang ini merupakan biaya overhead proyek besar.

8. Owner harus meminimalkan persyaratan terkait overhead dalam dokumen kontrak mereka sehingga biaya proyek overhead dapat dikurangi. Ini akan menjadi manfaat timbal balik bagi pemilik proyek.

9. Kontraktor dan pemilik proyek harus menyelesaikan masalah pembayaran yang tertunda agar dapat mengurangi biaya berlebih. 


\section{METODOLOGI PENELITIAN}

\section{Identifikasi variabel pengurangan biaya overhead lapangan berdasarkan studi literatur}

Dalam penelitian ini, digunakan teknik studi literatur untuk variabel pengurangan biaya overhead lapangan yang dominan di proyek gedung bertingkat tinggi di Jakarta . Studi literatur ini sendiri dilakukan dari berbagai jurnal. Lalu membuat tabel seperti pada tabel 1. untuk mengetahui hasil dari berbagai jurnal dan kelebihan dan kekurangan dari jurnal tersebut. Hal itu dilakukan untuk memudahkan peneliti dalam mencari identifikasi jenis pengurangan biaya overhead lapangan yang dominan pada gedung bertingkat tinggi di Jakarta

\begin{tabular}{|c|c|c|c|c|}
\hline No & Jurnal & $\begin{array}{c}\text { Jumlah Sampel dan } \\
\text { Metodologi }\end{array}$ & Hasil & $\begin{array}{c}\text { Kelebihan dan } \\
\text { Kekurangan }\end{array}$ \\
\hline 1 & & & & \\
\hline 2 & & & & . \\
\hline
\end{tabular}

\section{Metode penyusunan kuisioner}

Setelah melakukan tabulasi, langkah selanjutnya adalah menyusun kuisioner berdasarkan variabel yang telah diperoleh biaya overhead dengan respondennya adalah Project Manager atau Site Manager Kuisioner ini dibuat dengan menggunakan skala likert. Skala Likert menurut Djaali (2008) ialah skala yang dapat dipergunakan untuk mengukur sikap, pendapat, dan persepsi seseorang atau sekelompok orang tentang suatu gejala atau fenomena pendidikan. Pada Kuisioner ini skala likert dengan nilai 1 (satu) merupakan nilai minimal (tidak setuju) sampai nilai 5 (lima) merupakan nilai maksimum (sangat setuju). Untuk menjawab pertanyaan-pertanyaan yang diajukan, dapat dilakukan dengan memberikan tanda sialng (x) pada nomor yang dipilih pada skala likert seperti pada tabel 2.

Tabel 2. Skala Likert

\begin{tabular}{cc}
\hline Skala & Keterangan \\
\hline 1 & Tidak Setuju \\
\hline 2 & Kurang Setuju \\
\hline 3 & Cukup Setuju \\
\hline 4 & Setuju \\
\hline 5 & Sangat Setuju \\
\hline
\end{tabular}

Kuisioner disusun menjadi beberapa bagian, antara lain :

1. Kata Pengantar

2. Data Diri Responden

3. Data Proyek

4. Catatan

5. Isi kuisioner Mengenai Biaya Overhead

Contoh tabel pernyataan yang dikerjakan dalam kuisioner dapat dilihat pada tabel 3 dibawah ini : 
Tabel 3. Contoh tabel pernyataan dalam kuisioner

\begin{tabular}{lllllll}
\hline No & Pernyataan & 1 & 2 & 3 & 4 & 5 \\
\hline 1 & & & & & & \\
\hline 2 & & & & & & \\
\hline
\end{tabular}

\section{Distribusi dan pengumpulan data}

Kuisioner yang telah dibuat tersebut disebarkan ke proyek-proyek bangunan tinggi yang berada di Jakarta dan sekitarnya. Kuisioner ini didistribusikan kepada responden yaitu Project Manager atau Site Manager untuk mengumpulkan data dan juga hasil jawaban kuisioner yang diperlukan untuk mengolah data tentang jenis -jenis pengelolaan. Setelah data terkumpul, hasil dari kuisioner tersebut disusun kembali dalam bentuk tabel untuk memudahkan dalam mengerjakan tahap selanjutnya. Contoh penyusunan hasil kuisioner dapat dilihat pada tabel 4.

Tabel 4. Data Hasil Kuisioner

\begin{tabular}{ccccccc}
\hline No & Butir Pernyataan & 1 & 2 & 3 & 4 & 5 \\
\hline 1 & A & B & C & D & E \\
\hline 2 & A & B & C & D & E \\
\hline 3 & A & B & C & D & E \\
\hline
\end{tabular}

\section{Metode analisis faktor}

Pada penelitian ini, digunakan explanatory factor analysis, yaitu teknik di mana faktor yang akan terbentuk berupa variabel yang belum dapat ditentukan sebelum analisis dilakukan. Tujuan dari explanatory factor analysis ini untuk menemukan hubungan antarvariabel baru, sehingga dapat dibuat kelompok variabel laten baru yang lebih sedikit dari jumlah variabel awal.

\section{Pengolahan data}

Pengolahan data dalam penelitian ini menggunakan analisis faktor. Analisis faktor dilakukan dengan beberapa tahap yaitu Uji KMO, uji Barlett, uji MSA, uji reabilitas dan pengelompokan faktor. Untuk memudahkan penelitian, faktorfaktor variabel menggunakan notasi seperti yang dapat dilihat pada tabel 5 . Semua analisis pada penelitian ini menggunakan software SPSS®. Hasil dari penelitian akan dijabarkan sebagai berikut.

Tabel 5. Variabel-Variabel Motivasi dan Disiplin Kerja

\begin{tabular}{cl}
\hline Notasi & \multicolumn{1}{c}{ Faktor Variabel } \\
\hline $\mathrm{X} 1$ & Nilai Kontrak \\
\hline $\mathrm{X} 2$ & Pengawasan yang tepat pada proyek \\
\hline $\mathrm{X} 3$ & Akurasi Penyelesaian Proyek \\
\hline $\mathrm{X} 4$ & Inovasi \\
\hline $\mathrm{X} 5$ & Pembayaran upah/ gaji yang tepat waktu \\
\hline $\mathrm{X} 6$ & Pengelolaan Kegiatan berbasis biaya \\
\hline $\mathrm{X} 7$ & Asuransi rendah \\
\hline $\mathrm{X} 8$ & $\begin{array}{l}\text { Melakukan review yang teratur / periodik pada laporan biaya } \\
\text { overhead }\end{array}$ \\
\hline $\mathrm{X} 9$ & Efektivitas pekerja \\
\hline
\end{tabular}




\section{Pengujian data}

Pengujian dilakukan dengan menggunakan bantuan software SPSS. Adapun teknik analisis data yang dilakukan dalam penelitian ini meliputi uji KMO, uji barlett, uji MSA, uji reliabilitas, dan pengelompokan factor.

\section{ANALISIS DAN PEMBAHASAN}

Dari hasil penyebaran kuesioner, didapat 30 kuesioner yang dapat digunakan untuk analisis data..

\section{Uji KMO, uji barlett,dan uji MSA}

Pada tabel 6 ,dapat diketahui bahwa hasil dari uji KMO adalah 0,568. Hal ini menunjukkan bahwa sampel data yang digunakan mencukupi karena hasil uji KMO tersebut lebih dari 0,5. Pada uji Bartlett Test of Sphericity, siginifikansi yang didapatkan adalah 0,00 dan lebih kecil daripada 0,5 . Karena telah memenuhi persyaratan yang ada, maka data dapat dianalisis lebih lanjut.

Tabel 7 Hasil Uji KMO dan Uji Barlett

\begin{tabular}{lcr}
\hline $\begin{array}{l}\text { Kaiser-Meyer-Olkin } \\
\text { Sampling Adequacy. }\end{array}$ & Measure of & 0.568 \\
\hline & $\begin{array}{l}\text { Approx. } \\
\text { Chi-Squar, }\end{array}$ & 71.083 \\
$\begin{array}{l}\text { Bartlett's Test } \\
\text { of Sphericity }\end{array}$ & Df & 36 \\
& Sig. & 0 \\
\hline
\end{tabular}

Setelah uji KMO dan uji Bartlett, dilakukan uji MSA untuk mengetahui kecukupan sampling setiap faktor yang ada. Apabila nilai MSA yang didapatkan kurang dari 0,5 maka analisis harus diulangi kembali dengan mengeluarkan faktor yang tidak memenuhi persyaratan A. dari uji MSA dapat dilihat pada tabel 8.

Tabel 8 Hasil uji MSA

\begin{tabular}{|c|c|c|c|c|c|c|c|c|c|c|}
\hline & & $\mathrm{X} 1$ & $\mathrm{X} 2$ & X3 & $\mathrm{X} 4$ & X5 & X6 & $\mathrm{X} 7$ & $\mathrm{X} 8$ & X9 \\
\hline \multirow{9}{*}{$\begin{array}{l}\text { Anti-image } \\
\text { Covarianc } \\
e\end{array}$} & $\mathrm{X} 1$ & 0.878 & 0.069 & -0.082 & 0.119 & -0.089 & -0.066 & -0.212 & -0.021 & 0.032 \\
\hline & $\mathrm{X} 2$ & 0.069 & 0.247 & -0.194 & 0.099 & -0.072 & -0.114 & 0.008 & -0.138 & -0.129 \\
\hline & X3 & -0.082 & -0.194 & 0.278 & -0.136 & 0.071 & -0.045 & 0.003 & 0.057 & 0.121 \\
\hline & $\mathrm{X} 4$ & 0.119 & 0.099 & -0.136 & 0.49 & -0.227 & -0.045 & -0.162 & -0.189 & -0.242 \\
\hline & $\mathrm{X} 5$ & -0.089 & -0.072 & 0.071 & -0.227 & 0.707 & -0.038 & 0.134 & 0.182 & -0.045 \\
\hline & X6 & -0.066 & -0.114 & -0.045 & -0.045 & -0.038 & 0.608 & 0.054 & 0.121 & 0.004 \\
\hline & X7 & -0.212 & 0.008 & 0.003 & -0.162 & 0.134 & 0.054 & 0.807 & -0.105 & 0.044 \\
\hline & X8 & -0.021 & -0.138 & 0.057 & -0.189 & 0.182 & 0.121 & -0.105 & 0.713 & 0.076 \\
\hline & $\mathrm{X} 9$ & 0.032 & -0.129 & 0.121 & -0.242 & -0.045 & 0.004 & 0.044 & 0.076 & 0.655 \\
\hline \multirow{6}{*}{$\begin{array}{l}\text { Anti-image } \\
\text { Correlatio } \\
n\end{array}$} & $\mathrm{X} 1$ & $.341^{\mathrm{a}}$ & 0.149 & -0.166 & 0.182 & -0.113 & -0.09 & -0.252 & -0.026 & 0.042 \\
\hline & $\mathrm{X} 2$ & 0.149 & $.567^{\mathrm{a}}$ & -0.741 & 0.285 & -0.172 & -0.295 & 0.019 & -0.328 & -0.322 \\
\hline & X3 & -0.166 & -0.741 & $.580^{\mathrm{a}}$ & -0.368 & 0.159 & -0.109 & 0.006 & 0.129 & 0.283 \\
\hline & $\mathrm{X} 4$ & 0.182 & 0.285 & -0.368 & $.508^{\mathrm{a}}$ & -0.386 & -0.083 & -0.257 & -0.32 & -0.427 \\
\hline & $\mathrm{X} 5$ & -0.113 & -0.172 & 0.159 & -0.386 & $.551^{\mathrm{a}}$ & -0.058 & 0.178 & 0.257 & -0.066 \\
\hline & X6 & -0.09 & -0.295 & -0.109 & -0.083 & -0.058 & $.831^{\mathrm{a}}$ & 0.077 & 0.183 & 0.006 \\
\hline
\end{tabular}


Tabel 8 Hasil Uji MSA (Lanjutan)

\begin{tabular}{cccccccccc}
\hline & $\mathrm{X} 1$ & $\mathrm{X} 2$ & $\mathrm{X} 3$ & $\mathrm{X} 4$ & $\mathrm{X} 5$ & $\mathrm{X} 6$ & $\mathrm{X} 7$ & $\mathrm{X} 8$ & $\mathrm{X} 9$ \\
\hline $\mathrm{X} 7$ & -0.252 & 0.019 & 0.006 & -0.257 & 0.178 & 0.077 & $.488^{\mathrm{a}}$ & -0.139 & 0.061 \\
\hline $\mathrm{X} 8$ & -0.026 & -0.328 & 0.129 & -0.32 & 0.257 & 0.183 & -0.139 & $.468^{\mathrm{a}}$ & 0.112 \\
\hline $\mathrm{X} 9$ & 0.042 & -0.322 & 0.283 & -0.427 & -0.066 & 0.006 & 0.061 & 0.112 & $563^{\mathrm{a}}$ \\
\hline
\end{tabular}

a. Measures of Sampling Adequacy(MSA)

Dari tabel hasil uji MSA, diketahui bahwa terdapat satu faktor yang tidak memenuhi persyaratan yaitu X1,X7,dan $\mathrm{X} 8$. Oleh karena itu, analisis harus diulangi kembali dengan mengeluarkan faktor X1,X7, dan X8.

Setelah dilakukan analisis ulang,dan mengeluarkan faktor X1,X7,dan X8 dapat dilihat bahwa pada uji KMO dan uji MSA (tabel 9 dan tabel 10) bahwa uji KMO dan uji MSA telah memenuhi syarat karena nilai dari kedua uji tersebut $>$ 0,5. Pada tabel 10 juga diketahui nilai dari signifikansi uji Bartlett berada dibawah 0,05. Artinya semua persyaratan validitas telah terpenuhi dan dapat dilanjutkan pada tahap selanjutnya.

Tabel 9 Hasil Uji KMO dan Uji Barlett

\begin{tabular}{llr}
\hline Kaiser-Meyer-Olkin Measure of Sampling Adequacy. & 0.638 \\
\hline & & \\
\cline { 2 - 3 } Bartlett's Test of Sphericity & Approx. Chi-Square & 58.341 \\
\cline { 2 - 3 } & & Df \\
\cline { 2 - 3 } & Sig. & 0
\end{tabular}

Tabel 10 Hasil Uji MSA

\begin{tabular}{|c|c|c|c|c|c|c|c|}
\hline & & $\mathrm{X} 2$ & X3 & $\mathrm{X} 4$ & X5 & X6 & X9 \\
\hline \multirow{6}{*}{$\begin{array}{l}\text { Anti-image } \\
\text { Covariance }\end{array}$} & $\mathrm{X} 2$ & 0.284 & -0.212 & 0.079 & -0.041 & -0.104 & -0.138 \\
\hline & X3 & -0.212 & 0.291 & -0.15 & 0.059 & -0.066 & 0.127 \\
\hline & $\mathrm{X} 4$ & 0.079 & -0.147 & 0.616 & -0.195 & 0.01 & -0.273 \\
\hline & $\mathrm{X} 5$ & -0.041 & 0.059 & -0.2 & 0.799 & -0.102 & -0.085 \\
\hline & X6 & -0.104 & -0.066 & 0.01 & -0.102 & 0.638 & -0.013 \\
\hline & X9 & -0.138 & 0.127 & -0.27 & -0.085 & -0.013 & 0.67 \\
\hline \multirow{6}{*}{$\begin{array}{l}\text { Anti-image } \\
\text { Correlation }\end{array}$} & $\mathrm{X} 2$ & $.614^{\mathrm{a}}$ & -0.739 & 0.189 & -0.086 & -0.245 & -0.316 \\
\hline & X3 & -0.739 & $.584^{\mathrm{a}}$ & -0.35 & 0.122 & -0.152 & 0.287 \\
\hline & $\mathrm{X} 4$ & 0.189 & -0.348 & $.605^{\mathrm{a}}$ & -0.278 & 0.016 & -0.425 \\
\hline & $\mathrm{X} 5$ & -0.086 & 0.122 & -0.28 & $.730^{\mathrm{a}}$ & -0.142 & -0.116 \\
\hline & X6 & -0.245 & -0.152 & 0.016 & -0.142 & $.880^{\mathrm{a}}$ & -0.019 \\
\hline & X9 & -0.316 & 0.287 & -0.43 & -0.116 & -0.019 & $.556^{\mathrm{a}}$ \\
\hline
\end{tabular}

Kemudian, dilakukan pengecekan pada tabel Communalities. Nilai dari hasil Extraction tersebut harus berada diatas 0,5. Extraction merupakan seberapa besar faktor yang akan terbentuk mampu menjelaskan suatu variabel. Dapat dilihat pada tabel 11 hasil dari Extraction memenuhi persyaratan maka analisis dapat dilakukan lebih lanjut. 
Tabel 11 Communalities

\begin{tabular}{lcc}
\hline \multicolumn{2}{c}{ Initial } & \multicolumn{2}{c}{ Extraction } \\
\hline $\mathrm{X} 2$ & 1.000 & 0.841 \\
\hline $\mathrm{X} 3$ & 1.000 & 0.836 \\
\hline $\mathrm{X} 4$ & 1.000 & 0.641 \\
\hline $\mathrm{X} 5$ & 1.000 & 0.536 \\
\hline $\mathrm{X} 6$ & 1.000 & 0.609 \\
\hline $\mathrm{X} 9$ & 1.000 & 0.623 \\
\hline
\end{tabular}

\section{Uji reliabilitas}

Metode Cronbach Alpha digunakan dalam uji reabilitas pada penelitian ini. Hasil dari uji reabilitas dapat dilihat pada tabel 12

Tabel 12 Hasil uji reliabilitas

\begin{tabular}{cc}
\hline Cronbach's Alpha & N of Items \\
\hline 0.737 & 6 \\
\hline
\end{tabular}

Dari hasil uji reabilitas, diketahui nilai Cronbach Alpha yang dihasilkan >0,5. Hal ini menunjukkan bahwa data yang digunakan pada penelitian ini dapat diandalkan dan dapat digunakan untuk analisis pada tahap selanjutnya, Dari tabel 12 dapat disimpulkan bahwa data penelitian ini memiliki reliabilitas yang sangat tinggi..

\section{Pengelompokan faktor}

Setelah semua asumsi terpenuhi, dapat dilakukan pengelompokkan faktor baru yang tidak saling berkorelasi. Terdapat 2 kelompok faktor baru yang terbentuk seperti yang dapat dilihat pada tabel 13 .

Tabel 13 Tabel Hasil Loading Factor

\begin{tabular}{lcc}
\hline & \multicolumn{2}{c}{ Component } \\
\cline { 2 - 3 } & 1 & 2 \\
\hline X3 & 0.909 & 0.103 \\
\hline X2 & 0.898 & 0.184 \\
\hline X6 & 0.765 & 0.155 \\
\hline X9 & 0.105 & 0.782 \\
\hline X4 & 0.24 & 0.764 \\
\hline X5 & 0.074 & 0.728 \\
\hline
\end{tabular}

Dari tabel loading faktor diatas, dapat dilihat seberapa besar variabel-variabel berkorelasi dengan faktor yang terbentuk. Penentuan kelompok faktor dengan cara melihat korelasi terbesar dari variabel tersebut. Maka anggota dari kelompok faktor yang terbentuk adalah : 
- Kelompok 1 : Pengawasan yang tepat pada proyek, Akurasi penyelesaian proyek, Pengelolaan Kegiatan Berbasis biaya

- Kelompok 2 : Inovasi, Pembayaran upah atau gaji yang tepat waktu, dan Efektivitas pekerja

Langkah terakhir dalam menentukan faktor adalah melihat tabel Component Transformation Matrix pada tabel 14. Pada component 1 dan 2 memiliki nilai diatas 0,5 maka dapat dikatakan bahwa kelompok faktor yang telah terbentuk telah tepat merangkum seluruh variabel yang ada.

Tabel 4.14 Component Transformation Matrix

\begin{tabular}{ccc}
\hline Component & 1 & 2 \\
\hline 1 & 0.817 & 0.576 \\
\hline 2 & -0.576 & 0.817 \\
\hline
\end{tabular}

Extraction Method: Principal Component Analysis.

Rotation Method: Varimax with Kaiser Normalization.

Semua asumsi dari analisis faktor telah terpenuhi.

\section{KESIMPULAN}

Dari hasil penelitian, dapat ditarik beberapa kesimpulan sebagai berikut:

1. Dari hasil pengurangan faktor pada data kuisioner menggunakan analisis faktor, didapatkan 6 faktor dengan membuang 3 faktor, 3 faktor yang dibuang tersebut adalah biaya overhead dimasukkan ke dalam nilai kontrak, asuransi rendah, melakukan review yang teratur / periodik pada laporan biaya overhead.

Setelah itu, didapatkan 2 kelompok variabel baru. Kelompok tersebut adalah:

- Kelompok 1: Pengawasan yang tepat pada proyek, Akurasi penyelesaian proyek, Pengelolaan Kegiatan Berbasis biaya

- Kelompok 2: Inovasi, Pembayaran upah/ gaji yang tepat waktu, Efektivitas pekerja

2. Dari ke 6 faktor tesebut, didapatkan 6 faktor yang telah diurutkan berdasarkan nilai tertinggi ke rendah :

- Akurasi penyelesaian proyek

- Pengawasan yang tepat pada proyek

- Pengelolaan Kegiatan berbasis biaya

- Efektivitas pekerja

- Inovasi

- Pembayaran upah/gaji yang tepat waktu

\section{DAFTAR PUSTAKA}

Abdul-Malak, M. A. U., El-Saadi, M. M. H. and Abou-Zeid, M. G.(2002).”Process model for administrating construction claims", Journal of Management in Engineering , ASCE, Vol.18 No.2, 84-94

American Association of Cost Engineering (AACE).(1992), Skills and Knowledge of Cost Engineering, 3rd Edition, ACE, West Virginia, 1992

Ariyanto, Hepy H,(2003). Hubungan Karakteristik Konsumen dalam Evaluasi

Assaf, Sadi A, Abdulaziz A. Bubshait, Sulaiman Atiyah, Mohammed Al-Shahri.(2001).”The Management of Construction company overhead costs". International Journal of Project Management, 295-303

Bennett, F. L .(2003). The Management of Construction: A Project Life Cycle Approach, University of Alaska, Fairbanks

Chan, C.T.W.(2012) "The principal factors affecting construction project overhead expenses: an exploratory factor analysis approach", Construction Management and Economics, Vol. 30, No. 10 (2012) : 903-914

Cilensek, R.(1991). “Understanding contractor overhead, Cost Engineering”, AACE, Vol.33 No. 12

Dagostino, F. R.(2002). Estimating in building construction, 6th edition, Prentice-Hall, Englewood Cliffs, N.J.

Djaali.(2008). Psikologi Pendidikan. Bumi Aksara, Jakarta

El-Sawy, Nabil I , and Ahmed El-Riyati.(2015). “An Overhead Costs Assessment for Construction Projects at Gaza Strip”. American Journal of Civil Engineering. Vol. 3, 95 - 101 
Faiz, P. M.(2007). Outsourcing (Alih Daya) dan Pengelolaan Tenaga Kerja pada Perusahaan. Tinjauan Yuridis Terhadap Undang-Undang Nomor 13 Tahun 2003 Tentang Ketenagakerjaan

Neil, J. M.(1981). Construction cost estimating for project control, Prentice-Hall,Englewood Cliffs, N.J

Soeharto, I.(1995). Manajemen proyek dari konseptual sampai operasional, Penerbit Erlangga, Jakarta

Swati S Patil and P. P. Bhangale. (2014). "Overhead Cost In Construction Industry". International Journal of Industrial Engineering \& Technology (IJIET). Vol. 4, 1-6

Taylor, G. R.(1994). "The Importance of Estimating Your Overhead.” Cost Engineering. Vol.36 (No.2), hal 15

Wattimury, H., et . al.(2015). Identifikasi Faktor-Faktor Cost Overrun Biaya Overhead Pada Proyek Pembangynan Manado Town Square III

Zack, J. G.(2001). "Calculation and recovery of home office overhead". American Association of Cost Engineering. $1-6$ 